\title{
Asuhan Kebidanan Intranatal pada Ny "N" dengan Persalinan Postterm di RSUD Syekh Yusuf Gowa 17 Juli 2018
}

\author{
${ }^{1}$ Eka Riska, ${ }^{2}$ Anieq Mumthiah Al-Kautsar, ${ }^{3}$ Andi Sitti Rahma
}

\begin{abstract}
ABSTRAK
Pendahuluan Persalinan postterm adalah persalinan yang usia kehamilannya lebih dari 42 minggu atau 294 hari. Diagnosa usia kehamilan lebih dari 42 minggu didapatkan dari perhitungan seperti rumus neagle atau dengan tinggi fundus uteri, resiko bagi ibu dengan persalinan postterm dapat berupa partus lama, inersia uteri dan perdarahan pasca salin serta meningkatnya tindakan obstetrik.
\end{abstract}

Metode Penelitian ini bertujuan untuk melaksanakan Manajemen Asuhan Kebidanan Intranatal Patologi pada Ny. "N" dengan Persalinan Postterm di RSUD. Syekh Yusuf tahun 2018 sesuai dengan 7 langkah Varney dan SOAP. Yaitu langkah I pengkajian data dasar, langkah II diagnosa masalah aktual, langkah III diagnosa masalah potensial, langkah IV tindakan segera/kolaborasi, langkah $\mathrm{V}$ menyusun rencana asuhan yang menyeluruh, langkah VI implementasi, langkah VII evaluasi.

Hasil Hasil dari studi kasus yang dilakukan pada Ny "N" dengan persalinan postterm, ditemukan hambatan yakni pada bayi dengan asfiksia sedang dan telah dilakukan penanganan sesuai kasus.

Kesimpulan dari studi kasus yaitu 7 langkah Varney dan SOAP yang digunakan untuk proses penyelesaian masalah kebidanan telah dilaksanakan pengkajian dan analisa data pada $\mathrm{Ny}$. "N" dengan persalinan postterm di RSUD. Syekh Yusuf Gowa 2018 dan telah dilakukan pengkajian pendokumentasian semua temuan dan tindakan yang telah dilaksanakan pada $\mathrm{Ny}$. "N" dengan hasil tidak ditemukannya kesenjangan teori dan kasus.
*UIN Alauddin Makassar

Kata kunci :

Persalinan Postterm;

7 langkah Varney

\section{PENDAHULUAN}

Persalinan postterm adalah persalinan yang usia kehamilannya lebih dari 42 minggu atau 294 hari. Diagnosa usia kehamilan lebih dari 42 minggu didapatkan dari perhitungan seperti rumus neagle atau dengan tinggi fundus uteri (Norma, Dwi, 2013: 202)

Persalinan postterm mempunyai hubungan erat dengan mortalitas dan morbiditas perinatal. Persalinan postterm berpengaruh pada janin, dalam kenyataannya persalinan postterm mempunyai pengaruh terhadap perkembangan janin sampai pada kematian janin akibat kekurangan zat makanan dan oksigen. Persalinan postterm mempunyai hubungan erat 
dengan mortalitas dan morbiditas perinatal. Sementara itu, resiko bagi ibu dengan persalinan postterm dapat berupa partus lama, inersia uteri dan perdarahan pasca salin serta meningkatnya tindakan obstetrik (Fadlun, Feryanto, 2013: 19).

Angka kejadian kehamilan postterm sebanyak 10\% dari seluruh jumlah kelahiran pertahun. Data statistik menunjukkan, angka kematian janin dalam kehamilan postterm lebih tinggi dibandingkan dalam kehamilan cukup bulan. Angka kematian kehamilan lewat waktu mencapai 5-7\%. Variasi insiden postterm berkisar antara 3,5-14\% (SDKI, 2012).

Permasalahan pada persalinan postterm pada ibu yakni meningkatkan morbilitas dan mortalitas yang diakibatkan dari makrosomia janin dan tulang tengkorak menjadi lebih keras sehingga menyebabkan terjadinya distosia persalinan,incordinate uterine action, partus lama, meningkatkan tindakan obstetrik, dan perdarahan postpartum (Fadlun, Feryanto, 2013:19). Berdasarkan data yang diperoleh, di Sulawesi Selatan, jumlah kematian ibu yang dilaporkan oleh dinas kesehatan kabupaten/kota mengalami peningkatan dan penurunan yakni pada tahun 2012 jumlah kematian ibu sebanyak 160 atau 110,26 per 100.000 kelahiran hidup, sedangkan pada tahun 2013 menurun menjdi 115 atau 78,38 per 100.000 kelahiran hidup, pada tahun 2014 kembali meningkat menjadi 138 orang atau 93,20 per 100.000 kelahiran hidup (Profil Kesehatan SulSel, 2014:19-27).

Menurut Ratnawati dan Yusnawati dalam penelitiannya, kehamilan postterm mempunyai resiko lebih tinggi dari kehamilan aterm, terutama terhadap kematian perinatal (antepartum, intrapartum, dan postpartum) berkaitan dengan aspirasi meconium dan asfiksia, kematian janin akibat persalinan postterm terjadi pada 30\% sebelum persalinan, $55 \%$ dalam persalinan, dan $15 \%$ pascanatal.

Permasalahan pada janin dalam persalinan postterm adalah plasenta tidak sanggup memberikan nutrisi dan pertukaran oksigen sehingga janin mempunyai resiko asfiksia sampai kematian dalam rahim, seperti pada data WHO pada tahun 2014, Angka Kematian Neonatus (AKN) di dunia adalah 26 per 1000 kelahiran hidup, dimana kelahiran dengan asfiksia menempati urutan kelima, yaitu sebanyak 9\% sebagai penyebab kematian ana k tertinggi di dunia setelah penyakit lain (WHO, 2014). 
Hal tersebut juga diperkuat berdasarkan hasil penilitian Laeli, dalam penelitiannya mengemukakan bahwa resiko kejadian asfiksia dari ibu yang mengalami kehamilan postterm sebanyak $61,7 \%$ dibandingkan ibu yang mengalami kehamilan aterm.

Angka Kematian Bayi (AKB) sendiri menurut Survey Penduduk Antar Sensus (SUPAS) pada tahun 2015 yaitu 22 per 100.000 kelahiran hidup, selain angka kematian bayi, berdasarkan Survey Demografi dan Kesehatan Indonesia (SDKI) tahun 2015, angka kematian ibu di Indonesia yaitu 305 per 100.000 kelahiran hidup yang mengalami penurunan dari tahun 2012 yakni sebesar 359 per 100.000 kelahiran hidup. Sedangkan AKB provinsi Sulawesi Selatan pada tahun 2011 sebayak 868 bayi atau 5,90 per 100.000 kelahiran hidup, pada tahun 2014 meningkat menjadi 1.056 bayi atau 7,23 per 100.000 kelahiran hidup. (Profil Kesehatan Sulsel, 2014:19-27).

Data yang diperoleh dari Dinas Kesehatan Kabupaten Gowa, AKI dan AKB mengalami penurunan, yaitu AKI pada tahun 2012 sebanyak 12 orang atau 106,53 per 100.000 kelahiran hidup, pada tahun 2013 menurun menjadi 10 orang atau 80 per 100.000 kelahiran hidup, dan pada tahun 2014 sebanyak 3 orang atau 24 per 100.000 kelahiran hidup. Sedangkan AKB pada tahun 2012 sebanyak 57 bayi atau 4,5 per 1000 kelahiran hidup. Pada tahun 2013 menjadi menurun menjadi 17 bayi atau 1 per 1000 kelahiran hidup, dan pada tahun 2014 sebanyak 10 bayi atau 1 per 1000 kelahiran hidup (Dinkes Kabupaten Gowa, 2014: 25-29).

Berdasarkan data Rekam Medik RSUD Syekh Yusuf Gowa, pada tahun 2015, angka kejadian postterm sebanyak 74 dari 1804 persalinan, tahun 2016 meningkat sebanyak 98 dari 1578 persalinan dan pada tahun 2017 sebanyak 20 dari 1180 persalinan.

Berdasarkan data diatas, pada tahun 2012 Kementrian Kesehatan meluncurkan program Expanding Maternal and Neonatal Survival (EMAS), dalam rangka menurunkan angka kematian ibu dan neonatal sebesar $25 \%$, program ini dilaksanakan di provinsi dan kabupaten dengan jumlah kematian ibu dan neonatal yang besar, yaitu Sumatera Utara, Banten, Jawa Barat, Jawa Tengah, Jawa Timur, dan Sulawesi Selatan. Dasar pemilihan provinsi tersebut disebabkan 52,6\% dari jumlah total kejadian kematian ibu di Indonesia berasal dari enam provinsi tersebut. Sehingga dengan menurunkan AKI dan AKB di enam provinsi tersebut, diharapkan akan dapat menurunkan AKI dan AKB di Indonesia secara signifikan (Depkes, 2016:104). 
Program Emas berupaya menurunkan AKI dan AKB dengan cara yaitu: pertama, meningkatkan kualitas pelayanan emergency obstetric dan bayi baru lahir minimal di 150 Rumah Sakit PONEK dan 300 Puskesmas/Balkemas PONED, dan yang kedua yaitu memperkuat sistem rujukan yang efisien dan efektif antara puskesmas dan Rumah Sakit.

Berdasarkan Kemenkes 900 tahun 2002 tentang registrasi dan praktik bidan dan memperhatikan draf ke VI kompetensi inti bidan yang disusun oleh International Confederation Of Midwife (ICM) Februari 1999, kompetensi bidan yang mencakup dan berhubungan dengan judul diatas dalam pemberian asuhan yakni:

1. Bidan memiliki persyaratan pengetahuan dan keterampilan dari ilmu-ilmu sosial, kesehatan masyarakat, dan etik yang membentuk dasar asuhan yang bermutu tinggi sesuai dengan budaya, untuk wanita, bayi baru lahir dan keluarganya.

2. Bidan memberikan as uhan bermutu tinggi serta tanggap terhadap budaya setempat selama persalinan, memimpin persalinan yang bersih, aman, menangani situasi kegawatdaruratan tertentu untuk mengoptimalkan kesehatan wanita dan BBL.

3. Bidan memberikan asuhan yang bermutu tinggi komperehensif kepada BBL, sampai dengan 1 bulan. Adapun peran bidan dalam menangani masalah asfiksia pada bayi baru lahir tercantum dalam Standar Pelayanan Kebidanan (SPK) pada standard 24 yakni penanganan asfiksia neonatorum yang dilakukan oleh bidan yaitu mengenali dengan tepat dengan asfiksia, serta melakukan tindakan yang sesuai, secara tepat, melakukan resusitasi dsb.

Berdasarkan uraian diatas, maka penulis tertarik untuk mengambil kasus asuhan kebidanan intaranatal pada ibu dengan persalina postterm, dengan mengkaji dan memaparkannya melalui karya tulis ilmiah guna mencari solusi dan memberikan asuhan yang sesuai.

\section{METODE PENELITIAN}

Jenis penelitian ini adalah studi kasus dengan pendekatan Manajemen Asuhan Kebidanan sesuai dengan 7 langkah Varney dan pendokumentasian dalam bentuk SOAP. Penatalaksanaan Asuhan dilakukan dengan pemberian asuhan yang sesuai standar operasional prosedur pada kasus yang diteliti yaitu persalinan postterm serta melakukan upaya pencegahan komplikasi terutama terjadinya gawat janin, partus lama, perdarahan 
postpartum, asfiksia dan Berat Badan Lahir Rendah (BBLR) serta dilakukannya pemantauan dan asuhan dari kala 1 sampai kala IV.

\section{HASIL PENELITIAN}

Penelitian ini dilakukan di RSUD Syekh Yusuf Gowa tepat dengan pembahasan tentang manajemen asuhan kebidanan intranatal pada Ny"N" dengan persalinan postterm di RSUD Syekh Yusuf Gowa 17 Juli 2018. Pembahasan ini dibuat berdasarkan landasan teoritis dan studi kasus yang dapat dianalisa secara teoritis untuk memudahkan memahami kesenjangan dan kesesuaian yang terjadi pada kasus ini dengan berdasarkan pada pendekatan asuhan kebidanan dengan tujuh langkah varney yakni : pengumpulan data dasar, merumuskan diagnosis atau masalah potensial, melaksanakan tindakan segera atau kolaborasi, merencanakan tindakan asuhan kebidanan

\section{Kala I}

Pada kasus Ny"N" didapatkan data inpartu kala 1 fase aktif dengan pembukaan lengkap jam 16.10 wita, ibu merasa ada dorongan yang kuat untuk meneran, perasaan ingin BAB, dengan his 5x dalam 10 menit durasi 40-45 detik, DJJ terdengar jelas kuat dan teratur serta tanda-tanda vital dalam batas normal.

Hasil evaluasi didapatkan bahwa pembukaan sudah lengkap terjadi pada jam 16.10 wita, perlangsungan kala 1 berlangsung normal tidak mengalami gangguan ataupun penyulit, hal ini menunjukkan bahwa tidak ada kesenjangan antar teori dengan praktek.

\section{Kala II}

Berdasarkan pengkajian pada kasus Ny"N" kala II berlangsung dengan normal yaitu 30 menit dan bayi lahir spontan dengan asfiksia sedang, nilai apgar score 5/7 pada tanggal 17 Juli 2018 wita dengan berat badan lahir 3340 gram, panjang badan $51 \mathrm{~cm}$, jenis kelamin lakilaki, kontraksi uterus teraba keras dan bundar, TFU setinggi pusat. Sesuai dengan teori yang menyebutkan kala 2 normal jika prosesnya berlangsung selama 2 jam pada primigravida dan 1 jam pada multigravida (Oxorn, 2010). Dan menurut (Dewi, 2012) asfiksia sedang ditandai dengan frekuensi jantung 60-80 kali per menit, usaha napas lambat, tonus otot biasanya dalam keadaan baik, bayi masih bereaksi terhadap rangsangan, bayi tampak 
sianosis. Hal ini menunjukkan bahwa tidak ada kesenjangan antar teori dan praktek yang dilakukan.

\section{Kala III}

Pada kasus Ny"N" didapatkan hasil pemeriksaan keadaan ibu dalam keadaan normal ditandai dengan ttv dalam batas normal, kontraksi uterus baik ditandai dengan uterus teraba keras bulat dan bundar, tinggi fundus uteri setinggi pusat, sehingga dapat disimpulkan bahwa kala III berlangsung normal, serta tidak ada kesenjangan antara teori dengan praktek.

\section{Kala IV}

Pada kasus Ny"N" didapatkan bahwa kontraksi uterus baik, teraba keras dan bundar, tinggi fundus uteri 1 jari bawah pusat, kandung kemih kosong, jumlah perdarahan $\pm 140 \mathrm{cc}$, hasil evaluasi tersebut menunjukkan bahwa Kala IV berlangsung normal dan tidak ada penyulit serta tidak ada kesenjangan antara teori dengan praktek.

\section{PEMBAHASAN}

\section{Kala I}

Pada kasus Ny"N" didapatkan data inpartu kala 1 fase aktif dengan pembukaan lengkap jam 16.10 wita, ibu merasa ada dorongan yang kuat untuk meneran, perasaan ingin $\mathrm{BAB}$, dengan his 5x dalam 10 menit durasi 40-45 detik, DJJ terdengar jelas kuat dan teratur serta tanda-tanda vital dalam batas normal.

Hasil evaluasi didapatkan bahwa pembukaan sudah lengkap terjadi pada jam 16.10 wita, perlangsungan kala 1 berlangsung normal tidak mengalami gangguan ataupun penyulit, hal ini menunjukkan bahwa tidak ada kesenjangan antar teori dengan praktek. Permasalahan pada janin dalam persalinan postterm adalah plasenta tidak sanggup memberikan nutrisi dan pertukaran oksigen sehingga janin mempunyai resiko asfiksia sampai kematian dalam rahim, seperti pada data WHO pada tahun 2014, Angka Kematian Neonatus (AKN) di dunia adalah 26 per 1000 kelahiran hidup, dimana kelahiran dengan asfiksia menempati urutan kelima, yaitu sebanyak $9 \%$ sebagai penyebab kematian ana k tertinggi di dunia setelah penyakit lain (WHO, 2014). 
Hal tersebut juga diperkuat berdasarkan hasil penilitian Laeli, dalam penelitiannya mengemukakan bahwa resiko kejadian asfiksia dari ibu yang mengalami kehamilan postterm sebanyak $61,7 \%$ dibandingkan ibu yang mengalami kehamilan aterm.

Persalinan postterm adalah persalinan yang usia kehamilannya lebih dari 42 minggu atau 294 hari. Diagnosa usia kehamilan lebih dari 42 minggu didapatkan dari perhitungan seperti rumus neagle atau dengan tinggi fundus uteri (Norma, Dwi, 2013: 202)

Persalinan postterm mempunyai hubungan erat dengan mortalitas dan morbiditas perinatal. Persalinan postterm berpengaruh pada janin, dalam kenyataannya persalinan postterm mempunyai pengaruh terhadap perkembangan janin sampai pada kematian janin akibat kekurangan zat makanan dan oksigen. Persalinan postterm mempunyai hubungan erat dengan mortalitas dan morbiditas perinatal. Sementara itu, resiko bagi ibu dengan persalinan postterm dapat berupa partus lama, inersia uteri dan perdarahan pasca salin serta meningkatnya tindakan obstetrik (Fadlun, Feryanto, 2013: 19).

Dilihat dari keadaan ibu dengan kondisi usia kehamilan lebih bulan atau postterm maka peran seorang bidan yaitu tetap memberikan dukungan psikologis dan spiritual kepada ibu dan keluarga dengan senantiasa berdoa dan berdzikir kepada Allah swt. serta memberikan pemahaman yang logis dari mitos- mitos yang beredar dari kalangan masyarakat awam agar segala kesulitan yang dialami dimudahkan karena atas izin-Nya, serta diberikan kesabaran dan ketabahan hati serta kemudahan dalam proses persalinan. Dengan diberikan dukungan kepada ibu dan keluarga semata-mata untuk menjadikan hati ibu tenang dan siap fisik dan mental dalam menghadapi persalinan.

Masalah-masalah yang bisa terjadi dari persalinan postterm ini maka ibu dan keluarga berhak untuk mengetahuinya, oleh karena itu bidan berperan untuk tetap memberikan dukungan psikologis dan spiritual kepada ibu dan keluarga agar tetap berdoa dan berdzikir kepada Allah SWT. agar masalah-masalah tersebut tidak terjadi dan memberikan pemahaman bahwa Allah swt. tidak memberikan cobaan kepada umatnya diluar batas kemampuan umatnya sendiri. Dengan dukungan ini ibu yakin dengan ikhtiar serta tawakal pasti bisa dan mampu melewati persalinannya dengan lancar. 


\section{Kala II}

Berdasarkan pengkajian pada kasus Ny"N" kala II berlangsung dengan normal yaitu 30 menit dan bayi lahir spontan dengan asfiksia sedang, nilai apgar score 5/7 pada tanggal 17 Juli 2018 wita dengan berat badan lahir 3340 gram, panjang badan $51 \mathrm{~cm}$, jenis kelamin lakilaki, kontraksi uterus teraba keras dan bundar, TFU setinggi pusat.

Sesuai dengan teori yang menyebutkan kala 2 normal jika prosesnya berlangsung selama 2 jam pada primigravida dan 1 jam pada multigravida (Oxorn, 2010). Dan menurut (Dewi, 2012) asfiksia sedang ditandai dengan frekuensi jantung 60-80 kali per menit, usaha napas lambat, tonus otot biasanya dalam keadaan baik, bayi masih bereaksi terhadap rangsangan, bayi tampak sianosis. Hal ini menunjukkan bahwa tidak ada kesenjangan antar teori dan praktek yang dilakukan. Halam hal ini antisipasi kemungkinan masalah yang akan terjadi. Dalam penelitian sebelumnya menyebutkan masalah potensial yang mungkin terjadi pada ibu postterm adalah kala II lama, dan ruptur uteri, sedangkan pada bayi masalah yang mungkin terjadi adalah asfiksia mekonium (Wijayanti, 2014).

Persalinan yang lama dapat mengakibatkan tidak seimbangnya cairan elektrolit serta kekurangan cadangan glukosa sehingga mengakibatkan kelelahan. Kondisi kelelahan akan mengakibatkan kontraksi uterus kurang adekuat sehingga mengakibatkan persalinan lama (Joseph, 2010).

Pada kasus Ny"N" kala II berlangsung dengan normal yaitu 30 menit dan bayi lahir spontan dengan asfiksia sedang, nilai apgar score 5/7 pada tanggal 17 Juli 2018 wita dengan berat badan lahir 3340 gram, panjang badan $51 \mathrm{~cm}$, jenis kelamin laki-laki, kontraksi uterus teraba keras dan bundar, TFU setinggi pusat. Sesuai dengan teori yang menyebutkan kala 2 normal jika prosesnya berlangsung selama 2 jam pada primigravida dan 1 jam pada multigravida (Oxorn, 2010). Dan menurut (Dewi, 2012) asfiksia sedang ditandai dengan frekuensi jantung 60- 80 kali per menit, usaha napas lambat, tonus otot biasanya dalam keadaan baik, bayi masih bereaksi terhadap rangsangan, bayi tampak sianosis. Hal ini menunjukkan bahwa tidak ada kesenjangan antar teori dan praktek yang dilakukan. 


\section{Kala III}

Pada kasus Ny"N" didapatkan hasil pemeriksaan dalam keadaan normal ditandai dengan uterus teraba keras dan bundar, tinggi fundus uteri setinggi pusat yang berarti kala III berlangsung normal, serta tidak ada kesenjangan antara teori dan praktek yang dilakukan.

Berdasarkan teori yang didapatkan asuhan persalinan kala III dimulai segera setelah bayi sampai lahirnya plsenta yang berlangsung tidak lebih dari 30 menit. Setelah bayi lahir uterus teraba keras dengan fundus uteri agak di atas pusat untuk melepaskan plasenta dari dindingnya. Tanda-tanda terlepasnya plasenta yaitu perubahan bentuk dan tinggi fundus uteri, tali pusat memanjang, tali pusat terlihat menjulur keluar melalui vulva, semburan darah tibatiba (Walyani, 2015).

Pada kasus Ny "N" dilakukan intervensi yang sesuai yaitu pemberian oksitosin, peregangan tali pusat dan masase uterus. Periksa tinggi fundus uteri untuk memastikan tidak ada janin, pemberian oksitosin dilakukan setelah 1 menit bayi lahir. Setelah itu, suntikkan oksitosin secara IM di sepertiga bagian atas paha ibu dan segera lakukan IMD.

Pada kasus Ny"N" melakukan pemberian oksitosin secara IM, kemudian melakukan peregangan tali pusat terkendali untuk melahirkan plasenta, lakukan masase uterus setelah plasenta lahir. Proses pelepasan dan pengeluaran plasenta berlangsung normal tanpa penyulit. Plasenta lahir 10 menit setelah bayi lahir yaitu jam 16.50 WITA, plasenta lahir lengkap dengan kotiledon dan selaput ketuban utuh, perdarahan $\pm 200 \mathrm{cc}$ dan segera dilakukan IMD.

Dari implementasi yang telah dilakukan pada kasus Ny"N" didapatkan hasil pemeriksaan keadaan ibu dalam keadaan normal ditandai dengan ttv dalam batas normal, kontraksi uterus baik ditandai dengan uterus teraba keras bulat dan bundar, tinggi fundus uteri setinggi pusat, sehingga dapat disimpulkan nahwa kala III berlangsung normal, serta tidak ada kesenjangan antara teori dengan praktek.

\section{Kala IV}

Berdasarkan teori pada kala IV hal-hal yang harus diperhatikan yaitu kontraksi uterus baik, tidak ada perdarahan pervaginam, plasenta dan selaput ketuban lengkap, kandung kemih 
harus kosong, dan luka diperineum harus dirawat serta melihat keadaan umum ibu dan bayi (Dewi, 2012).

Pada kasus Ny"N" didapatkan bahwa kontraksi uterus baik, teraba keras dan bundar, tinggi fundus uteri 1 jari bawah pusat, kandung kemih kosong, jumlah perdarahan $\pm 140 \mathrm{cc}$, hasil evaluasi tersebut menunjukkan bahwa Kala IV berlangsung normal dan tidak ada penyulit serta tidak ada kesenjangan antara teori dengan praktek.

Teori mengatakan salah satu penyebab kematian ibu pada waku nifas adalah perdarahan postpartum.Kematian ibu disebabkan oleh infeksi, perdarahan dan atonia uteri. Maka dengan demikian, pemantauan sangat penting selama 2 jam postpartum (Fika Nurul hidayat, 2012). Berdasarkan teori yang ada dan data pada kasus yang ada menujukkan bahwa tidak ada kesenjangan teori dan praktek yang dilakukan.

\section{KESIMPULAN DAN SARAN}

\section{A. KESIMPULAN}

1. Telah dilakukan pengkajian dan analisis data dasar pada Ny"N" dengan persalinan postterm di RSUD Syekh Yusuf. Pada kasus Ny"N" didapatkan data dasar dengan usia kehamilan 43 minggu 4 hari dan adanya pengeluaran air ketuban yang bercampur mekonium.

2. Telah dilakukan pengidentifikasian diagnosa/masalah actual pada Ny"N" dengan persalinan postterm di RSUD Syekh Yusuf tahun 2018: Ny"N" masuk dengan tanda dan gejala inpartu pada usia kehamilan 43 minggu 4 hari.

3. Telah dilakukan pengidentifikasian diagnosa/masalah potensial pada Ny"N" dengan persalinan postterm di RSUD Syekh Yusuf tahun 2018 di antisipasi terjadinya gawat janin, kala 1 memanjang, partus lama, asfiksia mekonium, perdarahan post partum

4. Telah dilakukan tindakan segera dan kolaborasi pada Ny"N" dengan persalinan postterm di RSUD Syekh Yusuf. Kolaborasi dilakukan untuk mempercepat persalinan, tidak ada indikasi untuk pelaksanaan tindakan segera karena tidak ada yang mengancam nyawa ibu.

5. Telah dilakukan penyusunan rencana tindakan asuhan (intervensi) pada Ny"N" dengan persalinan postterm di RSUD Syekh Yusuf, penilaian kemajuan persalinan, kondisi ibu dan janin. 
6. Telah dilakukan tindakan asuhan kebidanan pada Ny"N" dengan persalinan postterm di RSUD Syekh Yusuf tahun 2018. Pelaksanaan sesuai dengan intervensi dengan Bayi lahir normal setelah dipimpin selama 30 menit, dengan asfiksia sedang apgar score: 5/7.

7. Telah dilakukan evaluasi asuhan kebidanan pada Ny"N" dengan persalinan postterm di RSUD Syekh Yusuf. Kondisi ibu baik, tidak terjadi perdarahan, bayi mengalami asfiksia sedang dengan apgar score 5/7.

8. Telah dilakukan pendokumentasian semua temuan dan tindakan asuhan kebidanan pada Ny"N" dengan persalinan postterm di RSUD Syekh Yusuf Gowa Tahub 2018: semua hasil pemeriksaan dan penatalaksaan asuhan dituliskan secara lengkap direkam medik pasien.

B. SARAN

1. Bagi klien

a. Menganjurkan kepada ibu untuk mengkomsumsi makanan yang bergizi dan seimbang.

b. Menganjurkan ibu untuk banyak istirahat

c. Menganjurkan agar ibu menjaga kebersihan diri termasuk kebersihan genetalia

d. Menganjurkan ibu untuk memberikan Asi kepada bayinya sesering mungkin

2. Bagi bidan

Bidan sebagai tenaga kesehatan diharapkan mampu memeberikan pelayanan yang sesuai sehingga dapat membantu menurunkan angka kematian ibu (AKI) dan angka kematian bayi (AKB)

3. Bagi institusi

Untuk mendapatkan hasil manajemen asuhan asuhan kebidanan yang baik perlu menyediakan tenaga bidan yang professional untuk menunjang pelaksanaan tugas serta untuk meningkatkan keterampilan bidan.

\section{DAFTAR PUSTAKA}

Asri H dewi,dan Clevo P Cristine, Asuhan persalinan Normal, Yogyakarta: Nuha Medika. 2012.

Berawi M, Brillianningtyas L, Carolia N. The Relationship of Postterm Pregnanciesd and Premature Infants With Neonatal Asphyxia. http://juke.kedokteran.unila. ac.id/index.php/majority/artic le/view/294/292. (2 Juli 2018).

Damayanti, Ika, dkk. Buku Ajar Asuhan Kebidanan Komprehensif Pada Ibu Bersalin Dan Bayi Baru Lahir. Yogyakarta: Deepublish.2014. 
Depertemen Kesehatan Republik Indonesia. Profil Kesehatan Republik Indonesia. 2016.

Dewi Ratna Pudiastuti. Asuhan Kebidanan Pada Hamil Normal dan Patologi. Yogyakarta:

Nuha Medika. 2012.

Dinas Kesehatan Kabupaten Gowa, Profil Kesehatan Kabupaten Gowa, 2014.

http://pusdatin.kemkes.go.id/re source/download/profil/PROFI L KAB KOTA

2014/7306. Sulsesl kab Gowa 2014 (diakses tanggal 10 maret 2018).

Fadlun dan Achmad feriyanto. Asuhan Kebidanan Patologis. Jakarta: Salemba Medika. 2013.

Indrayani, dkk. Asuhan Persalinan dan dan Bayi Baru Lahir. Jakarta: Trans Info Media. 2013.

Kementrian Agama RI, Al-Qur'an terjemahan dan tajwid. Bandung: Jawa Barat, 2014.

Kuswanti, Ina dan Melina, Fitriani. Askeb II Persalinan. Yogyakarta: Pustaka Pelajar. 2016

Latifa Elisabeth M.F. Asuhan Kebidanan Kehamilan. Jakarta:IN MEDIA. 2013.

Manuaba, C. Gawat Darurat Obstetri- Ginekologi dan Obstetri Ginekologi Sosial untuk Profesi Bidan. Jakarta: EGC. 2008.

Maryunani, Anik. Asuhan kegawatdaruratan dalam Kebidanan. Jakarta: TIM. 2012.

Mochtar, Rustam. Sinopsis Obstetric Fisiologi Dan Patologi. Jakarta: EGC. 2013.

Nadyah. Kegawatdaruratan Neonatal, Anak Dan Maternal. Jakarta: PT Bina Pustaka Sarwono Prawihardjo. 2013.

Norma, nita, dkk. Asuhan Kebidanan Patologi. Yogyakarta: Nuha Medika. 2013

Nugroho, Taufan. Obstetri Dan Ginekologi. Yogyakarta: Nuha Medik a. 2011.

Oxorn Harry, William R. Forte. Ilmu Kebidanan: Patologi danFisiologi persalinan. Yogyakarta: Penerbit Andi. 2010.

Pemerintah Kota Makassar Dinas Kesehatan. "Profil Kesehatan Kota Makassar tahun 2014" 2015.

Prawirohardjo, Sarwono. Ilmu kebidanan. Jakarta: PT Bina Pustaka Sarwono Prawihardjo. 2011.

Prawirohardjo, Sarwono. Ilmu Kebidanan. Jakarta: PT Bina Pustaka Sarwono Prawihardjo. 2014.

Prawirohardjo, Sarwono. Ilmu kebidanan. Jakarta: PT Bina Pustaka Sarwono Prawihardjo. 2015.

Qadarshi laeli, Putri Andisetyana Hanifa. Hubungan Kehamilan Postterm Dengan Kejadian Asfiksia Pada Bayi Baru Lahir.Yogyakarta. Jurnal Maternity And Neonatal jilid 1 halaman 2.

Ratnawati, Yusnawati Nani. Hubungan Kehamilan Serotinus Dengan Kejadian Asfiksia Pada Bayi Baru Lahir. Bantul Yogyakarta: Jurnal Kebidanan jilid 3 nomor 1 halaman 27-33.

Sari, Eka Puspita, dkk. Asuhan Kebidanan Persalinan. Jakarta: Trans Info Media. 2014

Rukiyah, Yeye Ai dan Lia Yulianti. Asuhan Kebidanan Patologi Kebidanan. Jakarta: Trans Info Media. 2010.

Shihab, Quraish. Tafsir Al-Mishbah Pesan, Kesan Dan Keserasian Al-Qur'an. Jakarta: Lentera Hati. 2009.

Sulistyowati, Endah. Perbandingan Antara Nilai Apgar Pada Bayi Prematur dengan Bayi Postmatur Di Rsud Temanggung Tahun 2013.

Susiloningtyas Is dan Yanik Purwanti. Kajian Pengaruh Manajemen Aktif Kala III Terhadap Pencegahan Perdarahan Postpartum. http://jurnal.unissula.ac.id/inde x.php/majalahilmiahsultanagun g/article/view/73/67 . (2 Juli 2018).

Varney, Hellen. Buku Ajar Asuhan Kebidanan. Jakarta: 2002. 
Walyani Elisabeth S. Kebidanan Persalinan dan Bayi Baru 2012. http:stikeskusumahusada.ac.id/ digilib/files/disk1/2/01-gdl- dianwidyas-80-1-dianwidi.pdf.

Wijayanti, Erna dkk, Hubungan Kehamilan Lewat Waktu Dengan Kejadian Asfiksia bayi baru lahir diRSUD dr.R.Koesma Tuban. http://Ippm.stikesnu.com/wp- content/uploads/2014/02/5- jurnal-B-Erna -ailiyatiQ- klik.pdf.

Word Health Organization. Profil Kesehatan dan Pembangunan Perempuan di Indonesia. Bakti Husada. 2014.

Yulifah, Rita, dkk. Konsep Kebidanan. Jakarta Selatan: Salemba Medika. 2014. 